\title{
Interpretasi Filter Fraser dan Karous-Hjelt Pada Data VLF-EM Untuk Mengidentifikasi Air Lindi di Area TPA Ngipik
}

\author{
Khairul Yadi, Dwa Desa Warnana, Juan Pandu G.N.R, Nila Sutra, dan Ria Asih A. Soemitro \\ Departemen Teknik Geofisika, Jurusan Teknik Sipil, Fakultas Teknik Sipil dan Perencanaan, \\ Institut Teknologi Sepuluh Nopember (ITS) \\ e-mail:dwa_desa@geofisika.its.ac.id
}

\begin{abstract}
Abstrak-Telah dilakukan penelitian untuk mendeteksi keberadaan air lindi dengan metode VLF dimana pengolahan data yang dilakukan menggunakan Filter Fraser dan KarousHjlet. Hasil filter Fraser menghasilkan perpotongan grafik Inphase dan Quadrature yang mana anomali dapat dilihat jika grafik tersebut berpotongan pada saat Inphase negatif dan Quadrature positif sedangkan hasil Filter Karous-Hjelt menghasilkan penampang 2 dimensi dengan parameter rapat arus. Dari hasil penelitian diperoleh keberadaan air lindi ditunjukkan oleh adanya anomali konduktif pada lintasan 1 berada pada posisi $75-125 \mathrm{~m}, 140-160 \mathrm{~m}$ dan $210-230 \mathrm{~m}$, untuk Lintasan 2 berada pada posisi 20-25 m dan 75-135 m, sedangkan Lintasan 3 berada pada posisi 20-50m, 75-170 m dan 210-250 m. Hasil Filter Fraser dan Karous-Hjelt bisa digunakan untuk mendeteksi keberadaan air lindi yang diinterpretasi secara kualitatif dengan adanya anomali yang bersifat konduktif, namun hanya bisa melihat anomali secara lateral (horizontal).
\end{abstract}

Kata Kunci-VLF, Air Lindi, Konduktif.

\section{PENDAHULUAN}

$\mathrm{S}$ AMPAH yang tertimbun di Tempat Pembuangan Akhir (TPA) Ngipik mengandung zat organik, jika hujan turun akan menghasilkan air lindi dengan kandungan mineral dan zat organik tinggi yang bersifat konduktif, bila kondisi aliran air lindi dibiarkan mengalir kepermukaan tanah dapat menimbulkan efek negatif bagi lingkungan sekitarnya.

Pendeteksian air lindi bisa diketahui menggunakan metode VLF-EM. Data yang diperoleh dari pengukuran VLF-EM berupa posisi, Inphase, Quadrature, Tilt, dan Tfield. Untuk menampilkan karakteristik anomali konduktif/resistif bawah permukaan pada penelitian ini digunakan data inphase dan quadrature yang kemudian dilakukan pengolahan menggunakan Filter Fraser dan Filter Karous-Hjelt [1][2].

\section{DASAR TEORI}

\section{A. Filter Fraser}

Prinsip dasar dari Filter Fraser adalah menggunakan 4 buah data pada titik pengukuran yang berurutan, dengan cara mengurangkan jumlah dari data ke-3 dan ke-4 terhadap jumlah dari nilai data ke-1 dan data ke-2. Kemudian diplot pada titik tengah antara data ke-2 dan data ke-3. Secara matematis filter Fraser persamaannya adalah :
Dengan :

$$
\mathrm{F}_{n}=\left(\mathrm{H}_{\mathrm{n}+2}+\mathrm{H}_{\mathrm{n}+3}\right)-\left(\mathrm{H}_{\mathrm{n}}+\mathrm{H}_{\mathrm{n}+1}\right)
$$

$\mathrm{F}_{\mathrm{n}}=$ Nilai Fraser terhitung

$\mathrm{H}_{\mathrm{n}}=$ data pada titik ke $\mathrm{n}$

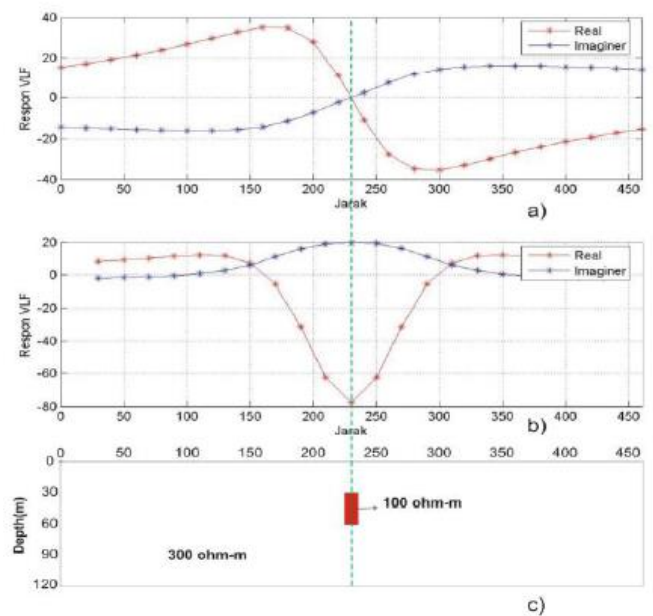

Gambar 1. Contoh Ilustrasi Pengolahan menggunakan Filter Fraser a). Data Observasi lapangan b). Hasil Filter Fraser c). Ilustrasi Anomali

\section{B. Filter Karous-Hjelt}

Filter Karous-Hjelt menghasilkan persebaran anomali bawah permukaan berdasarkan parameter rapat arus. Hasil yang diperoleh dari filter ini berupa peta kontur 2 dimensi dengan kedalam yang masil bersifat semu. Pengolahaan data menggunakan filter Karous-Hjelt sesuai dengan persamaan berikut :

$$
\begin{aligned}
\mathrm{KH}_{n}=0.102 \mathrm{H}_{\mathrm{n}-3}-0.059 \mathrm{H}_{\mathrm{n}-2}+0.561 \mathrm{H}_{\mathrm{n}-1}-0.561 \mathrm{H}_{\mathrm{n}+1} \\
+0.059 \mathrm{H}_{\mathrm{n}+2}-0.102 \mathrm{H}_{\mathrm{n}+3}
\end{aligned}
$$

dengan :

$\mathrm{KH}_{\mathrm{n}}=$ Nilai Karous-Hjelt terhitung

$\mathrm{H}_{\mathrm{n}}=$ data pada titik ke $\mathrm{n}$

\section{METODE PENELITIAN}

\section{A. Lokasi Penelitian}

Secara Geografis TPA Ngipik berada di antara $7^{0}$ 9'10.6" S dan $112^{0} 37^{\prime} 55.41^{\prime \prime}$ E. TPA Ngipik berada di area PT Semen 
Indonesia Tbk yang lokasinya berdekatan langsung dengan dua telaga Ngipik, Kabupaten Gresik.

\section{B. Metode Pengukuran}

Berikut ini lintasan pengukuran VLF pada lokasi penelitian.

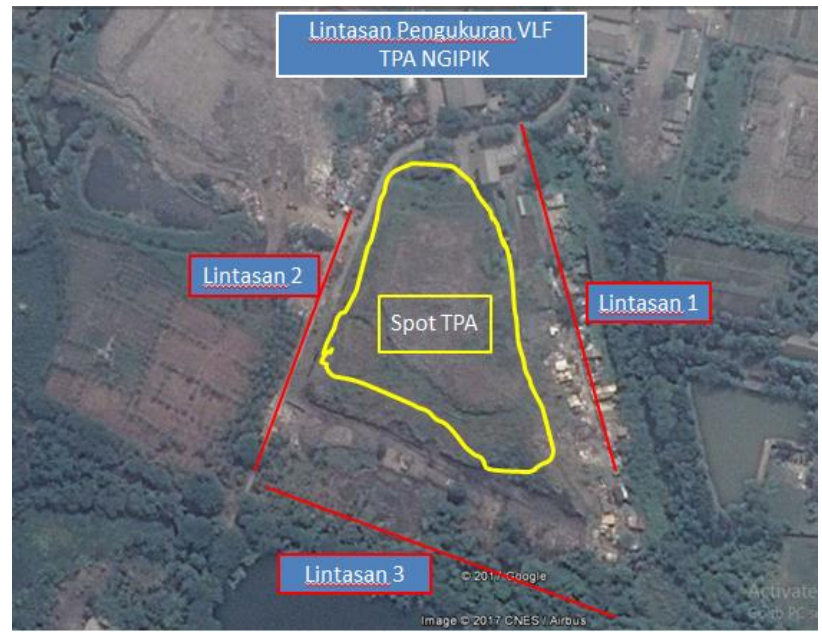

Gambar 2. Lintasan Pengukuran

Akuisisi lapangan yang terdiri dari 3 lintasan yang menyebar di area TPA Ngipik dengan spasi 5 meter untuk setiap lintasan pengukuran.

\section{HASIL DAN DISKUSI}

Intepretasi kualitatif dengan metode yang dikembangkan oleh Fraser dan Karous-Hjelt. Fraser menghasilkan perpotongan grafik Inphase dan Quadrature yang mana anomali dapat dilihat jika grafik tersebut berpotongan pada saat Inphase negatif dan Quadrature positif sedangkan KarousHjelt menghasilkan penampang 2 dimensi dengan parameter rapat arus.

Untuk menganalisa anomali pada hasil filter fraser dapat dilihat dari tren kurva Inphase dan Quadrature, hasilnya didapat dari perpotongan kurva tersebut. Sedangkan untuk menganalisa hasil filter karous-hjelt, anomali ditentukan dengan melihat skala warna rapat arus. Nilai rapat arus yang tinggi (positif) diidentifikasi sebagai anomali yang paling konduktif.
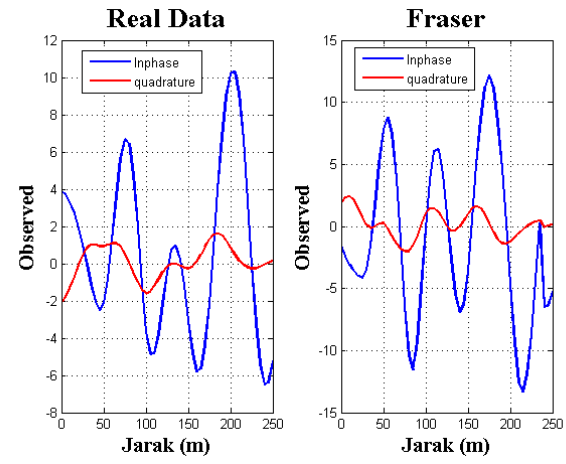

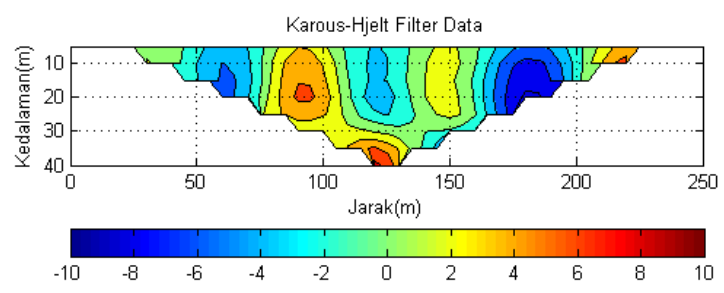

Gambar 3. Hasil Filter Lintasan 1

Dari Gambar 3. terlihat bahwa posisi anomali konduktif dari filter Fraser diperkiran berada pada meter 20-45 m, 75-120 m, 140-160 m dan 210-230 m. Hasil dari penentuan anomali dengan filter Fraser akan dikomparasikan dengan filter Karous-Hjelt, hal ini akan dilakukan agar hasil analisa kualitatif lebih akurat. Nilai rapat arus yang tinggi (positif) diidentifikasi sebagai anomali yang paling konduktif. Berdasarkan hasil filter Gambar 4, diduga anomali konduktif berada pada posisi $75-125 \mathrm{~m}, 140-160 \mathrm{~m}, 210-230 \mathrm{~m}$.
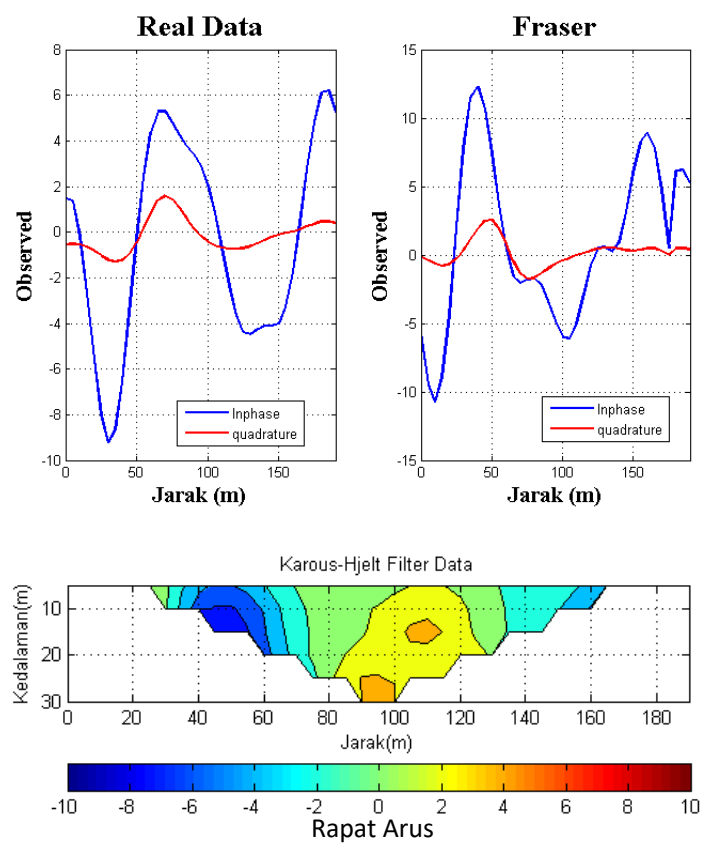

Gambar 4. Hasil Filter Lintasan 2

Dari Gambar 4. terlihat bahwa posisi anomali konduktif dari filter Fraser diperkiran berada pada meter 0-25 m, dan 80$120 \mathrm{~m}$. Nilai rapat arus yang tinggi (positif) diidentifikasi sebagai anomali yang paling konduktif. Berdasarkan hasil filter Gambar 5, diduga anomali konduktif berada pada posisi 20-25 m dan 75-135m. 

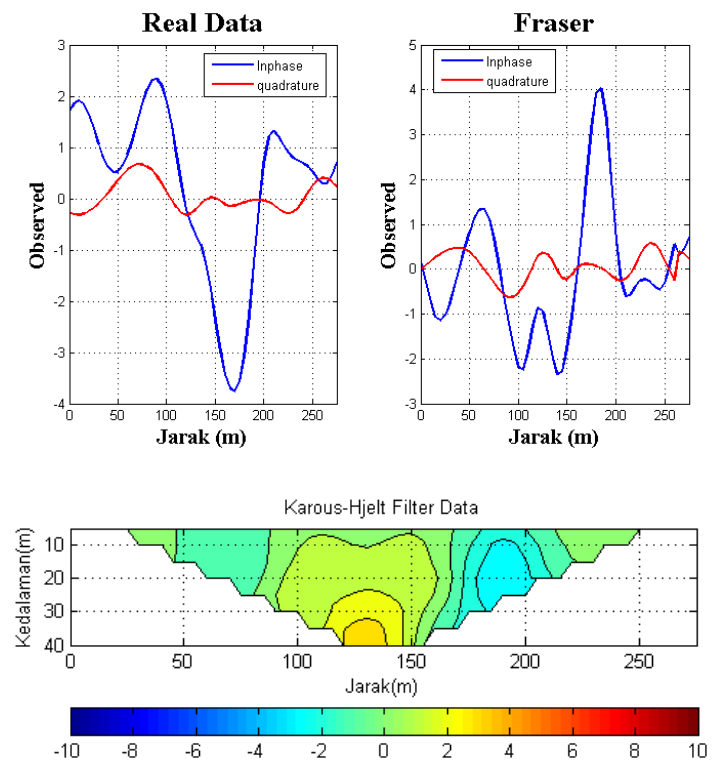

Gambar 5. Hasil Filter Lintasan 3

Dari Gambar 5. terlihat bahwa posisi anomali konduktif dari filter Fraser diperkiran berada pada meter $0-50 \mathrm{~m}, 80-170 \mathrm{~m}$ dan 200-250m. Nilai rapat arus yang tinggi (positif) diidentifikasi sebagai anomali yang paling konduktif. Berdasarkan hasil filter Gambar 5, diduga anomali konduktif berada pada posisi 20-50m, 75-170m dan 210-250 m.

\section{KESIMPULAN/RINGKASAN}

1. Anomali konduktif yang diprediksikan sebagai Air Lindi pada lintasan 1 berada pada posisi 75-125m, 140-160m, 210-230m. Lintasan 2 berada pada posisi 20-25 m dan 75$135 \mathrm{~m}$. Lintasan 3 berada pada posisi $20-50 \mathrm{~m}, 75-170 \mathrm{~m}$ dan 210-250 m.

2. Filter Fraser dan Karous-Hjelt bisa digunakan untuk mendeteksi keberadaan air lindi yang bisa diinterpretasi secara kualitatif dengan adanya anomali yang bersifat konduktif (rapat arusnya tinggi), namun hanya bisa melihat anomali secara lateral (horizontal) sedangkan untuk kedalaman anomali masih bersifat semu (pseudo).

\section{. UCAPAN TERIMA KASIH}

Penulis mengucapakan terima kasih kepada saudari Nila Sutra atas dukungan dana penelitian ini dari Penelitian Pendidikan Magister menuju Doktor untuk Sarjana Unggul (PMDSU).

\section{DAFTAR PUSTAKA}

[1] Y.-H. Jeng, Y., Lin, M.-J., Chen, C.-S., Wang, "Noise Reduction and Data Recovery for a VLF Survey using a nonlinear Decompotition Methode, Geophysics," vol. 5, pp. F223-F235.

[2] F. A. M. at al Santos, "Mapping groundwater contamination around a landfill facility using the VLF-EM method-A case study," Cent. Geofis. da Univ. Lisboa, 2006. 